Journal of Management

Vol. XX No. X, Month XXXX 1-25

DOI: $10.1177 / 0149206315618013$

(C) The Author(s) 2015

Reprints and permissions:

sagepub.com/journalsPermissions.nav

\title{
When Family Supportive Supervisors Meet Employees' Need for Caring: Implications for Work-Family Enrichment and Thriving
}

\author{
Marcello Russo \\ Kedge Business School \\ Filomena Buonocore \\ University of Naples, Parthenope \\ Abraham Carmeli \\ Tel Aviv University \\ Liang Guo \\ Neoma Business School
}

This article presents two studies that examine the moderated multiple mediation model between Family Supportive Supervisors Behaviors (FSSB) and individual's thriving at work through psychological availability and work-family enrichment at conditional levels of need for caring. Drawing on the Resource-Gain-Development framework and self-determination theory, the results of the 6-month time-lagged data demonstrate, in Study 1 (Italian sample =156), that FSSB is associated with greater individual thriving at work via work-family enrichment and that this indirect relationship is significant exclusively for those who perceive a higher need for caring. In Study 2 (Chinese sample =356), the results demonstrate the relationship between FSSB and thriving at work is serially mediated by both psychological availability and work-family enrichment at the conditional level of need for caring. In particular, the results demonstrate that individuals with a higher need for caring responded more favorably to the presence of a family supportive supervisor than those experiencing a lower need for caring. Implications for research and practice are discussed.

\footnotetext{
Acknowledgments: We would like to thank Russell A. Matthews for his friendly review on earlier versions of this paper, Marc Ohana for his methodological advice, and professor Andrew F. Hayes for his advice for computing the index of moderated mediation. We are also grateful to Dr. Eden King, associate editor, and two anonymous reviewers for their helpful and constructive comments and suggestions.
}

Supplemental material for this article is available at http://jom.sagepub.com/supplemental

Corresponding author: Marcello Russo, Kedge Business School, Department of Management, 680 Cours de la Libération, 33405, Talence, France.

E-mail:marcello.russo@kedgebs.com 
Keywords: FSSB; psychological availability; work-family enrichment; thriving at work; need for caring; Italy; China

Supervisors represent a powerful source of help for employees to successfully balance their work and family roles (Hammer, Demsky, Kossek, \& Bray, in press; Hammer, Kossek, Zimmerman, \& Daniels, 2007). While formal family-friendly policies are important, research has shown that informal Family Supportive Supervisors Behaviors (FSSB) are even more critical than such policies for alleviating employees' work-family tensions (Hammer, Kossek, Yragui, Bodner, \& Hanson, 2009; Kossek, Pichler, Bodner, \& Hammer, 2011; Straub, 2012). This is because the efficacy of formal family-friendly policies (such as flexible schedule, teleworking, compressed work week, etc.) often depends on the informal discretion of supervisors, who can act as gatekeepers (Straub, 2012) by encouraging or dissuading employees from using them (Allen, 2001). Researchers have consistently found that FSSB is associated with reduced work-family conflict and improved work-family enrichment (Bagger \& $\mathrm{Li}$, 2014; Las Heras, Trefalt, \& Escribano, 2015; Matthews, Mills, Trout, \& English, 2014; OdleDusseau, Britt, \& Greene-Shortridge, 2012; Wayne, Casper, Allen, \& Matthews, 2013).

However, despite the mounting evidence of benefits associated with FSSB, we know relatively little about the underlying process through which FSSB influences work and family outcomes (Straub, 2012). Unveiling what mechanisms and resources are prompted in the target population by virtue of the presence of a family supportive supervisor is necessary to develop a more complete understanding of proximal and distal outcomes of FSSB. In this article, drawing on the Resource-Gain-Development (RGD) framework (Wayne, Grzywacz, Carlson, \& Kacmar, 2007), we examine a serial multiple mediation model in which FSSB is associated with greater thriving at work (defined as an individual's "joint experience of learning and vitality at work" by Spreitzer, Sutcliffe, Dutton, Sonenshein, \& Grant, 2005: 538) through psychological availability and work-family enrichment. We suggest that psychological availability — which captures the individuals' perception of having all the necessary "physical, emotional, or psychological resources to personally engage at a particular moment" (Kahn, 1990: 714) - is a critical psychological resource that can be expanded in the presence of FSSB. This is because the presence of a family supportive supervisor signals to employees they may have access to all resources they need to engage in work and family roles. We suggest that this, in turn, can lead to greater work-family enrichment, as fully engaging in work and family roles is essential to gain further personal and contextual resources (ten Brummelhuis \& Bakker, 2012; Wayne, Randel, \& Stevens, 2006). Finally, we believe that thriving can be expanded in the presence of higher levels of work-family enrichment because the greater the resources individuals have at their disposal, the greater their capacity for investing in activities that favor their growth and self-development (Carmeli \& Russo, in press). Importantly, to demonstrate direction of causality between FSSB and thriving through psychological availability and workfamily enrichment, we have also tested supplementary models, reported in the Method section, which assume alternative causal relationships than the hypothesized ones.

Furthermore, as illustrated in Figure 1, drawing on self-determination theory (Deci \& Ryan, 1985), we suggest that the indirect relationship between FSSB and individual thriving at work may be better understood while considering the moderating role of individuals' need for caring, which we define as the extent to which individuals desire to feel valued, cared for, and 
Figure 1

The Hypothesized Serial Multiple Mediation Model

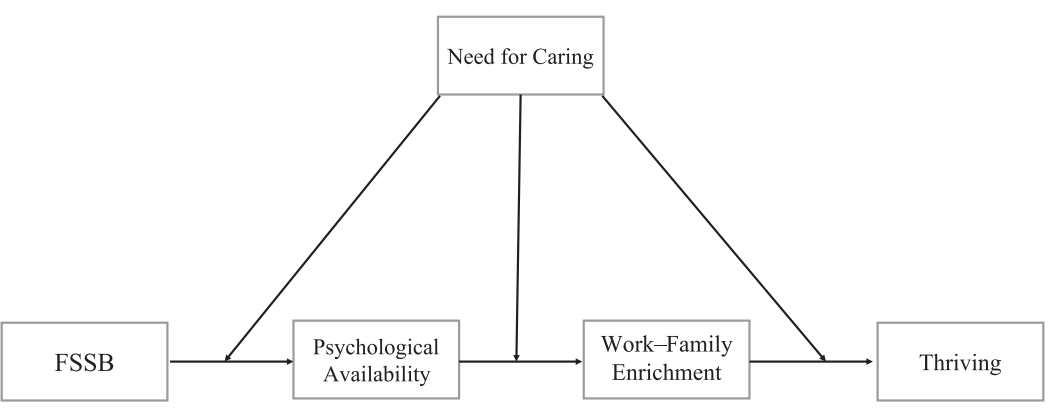

Note: FSSB and psychological availability were measured at Time 1 and work-family enrichment, need for caring, and thriving at Time 2. The time lag between Time 1 and Time 2 was 6 months.

appreciated by significant others. We contend that although all individuals value FSSB, as it is a helpful contextual resource (ten Brummelhuis \& Bakker, 2012; Voydanoff, 2005), those who have a higher need for caring may respond more favorably, as FSSB contributes to fulfilling their actual needs of being cared for. A focus on individual characteristics that moderate the effects of FSSB is theoretically and practically important. Theoretically, our study provides a complementary perspective to current FSSB research that has mainly focused on contextual factors - such as the presence of family-friendly benefits in the organization (Bagger \& Li, 2014), the exposure to a demanding family situation (Hammer, Kossek, Anger, Bodner, \& Zimmerman, 2011; Matthews, Mills et al., 2014), or the national context (Las Heras et al., 2015) - to examine potential boundary conditions of FSSB. Practically, pointing out who is more sensitive to FSSB would enable supervisors to allocate supportive resources more adequately by targeting those employees who are most in need of such support (Bagger \& Li, 2014).

Finally, a review of FSSB literature indicates that much of the research has been conducted in the United States (Las Heras et al., 2015), with only limited research conducted in non-U.S. settings. To address this limitation, we tested our model in two largely different countries, Italy (Study 1) and China (Study 2), using two samples of working adults living with a cohabiting partner and/or having at least one child to care for at home. This is important because examining the effects of FSSB in different cultural contexts provides an opportunity for theoretical refinement and empirical research extensions (Matthews, Mills et al., 2014), particularly because the cultural context can significantly impact the strength of family supportive supervision efforts (Shor, Greenhaus, \& Graham, 2013).

\section{Theoretical Background and Hypotheses}

\section{FSSB}

FSSB refers to discretionary supportive behaviors exhibited by supervisors towards employees' family roles (Hammer, Kossek, Bodner, \& Crain, 2013). It consists of four distinct dimensions: emotional support, instrumental support, role modeling, and creative workfamily management decisions. Emotional support refers to supervisors' emotional expression 
of concern towards the way the work impacts on employees' family and sympathy towards employees' family and personal life commitments (Hammer et al., 2009). Instrumental support refers to the day-to-day assistance and resources that supervisors provide to their employees to facilitate the management of work-family demands (Lapierre \& Allen, 2006). Role modeling refers to exemplary behaviors enacted by supervisors that can be a source of inspiration for employees because they are perceived as conducive of desirable work-family outcomes (Hammer et al., 2015; Koch \& Binnewies, 2015). Finally, creative work-family management consists of innovative actions initiated by supervisors with the goal to restructure work in a way that can both reduce individuals' work-family tensions and improve organizational outcomes (Hammer et al., 2009).

The RGD framework (Wayne et al., 2007) provides a solid theoretical foundation for our model, as it is fully rooted in positive organizational scholarship research (Cameron, Dutton, Quinn, \& Wrzesniewski, 2003) and conservation of resource theory (Hobfoll, 1989). The RGD framework focuses on individual and organizational enablers that can promote human development and allow an optimal individual functioning in work and family roles (Wayne et al., 2007). A basic assumption of the RGD framework is that individuals have a natural tendency to grow and achieve the highest level of functioning in each domain in which they are embedded. Critical to experiencing optimal functioning are the personal resources (skills, perspective, energies, conditions, human capital) and contextual resources (objects, support, social network) that individuals can gain when proactively engaging in domain-related activities and tasks (Wayne et al., 2007). Starting from these theoretical premises, we hereinafter develop our hypotheses regarding the relationships between FSSB, psychological availability, work-family enrichment, and thriving at work.

\section{FSSB, Psychological Availability, and Work-Family Enrichment}

As a starting point, we suggest that one important personal resource (psychological condition) that individuals can gain when working with a family supportive supervisor is psychological availability. Psychological availability is a positive mental state that reflects the individuals' capacity to be fully present in what they do, such that they become "attentive, connected, integrated and focused in their role performances" (Kahn, 1992: 322). Psychological availability manifests when an individual is personally accessible and intrinsically motivated to engage in what she or he is doing (i.e., contributing opinions and ideas, modeling openness and empathy towards others, and connecting to her or his self) (Kahn, 1990). Prior research has demonstrated that psychological availability increases when individuals perceive to have sufficient intellectual, emotional, and physical resources to successfully engage in a given situation (Kahn, 1990). Consistently, we suggest that in the presence of FSSB individuals' psychological availability is likely to be expanded. FSSB contributes to developing and retaining individuals' emotional, intellectual, and physical resources (Hammer et al., 2015), which can then be directed towards increasing their personal engagement in domain-related tasks and activities. When employees decide to approach their supervisors to seek help in handling their work-family problems, they need to feel reassured regarding the absence of negative repercussions associated with this decision. This is because moving towards others to seek help bears some risks, particularly that employees might be perceived as not sufficiently committed to work (Allen, 2001). FSSB signals to employees that the supervisor is accessible, is empathic, and has the goodwill intention to help them 
handle their family-related problems (Hammer et al., 2009). This can expand one's psychological availability, as employees feel they work in a safe environment wherein they can engage in an open and free exchange with their supervisor and express their family-related problems without the risk of being negatively judged because of this.

Hypothesis 1: FSSB is positively related to psychological availability.

We also hypothesize that psychological availability is associated with greater work-family enrichment. Kahn $(1990,1992,2001)$ argued that psychological availability is vital to foster greater engagement, because when individuals perceive they have adequate resources to cope with a specific situation (even when the particular demands in other domains are high), they are less distracted and are more able to focus on what they are doing. Accordingly, we contend that when employees experience psychological availability, the work-family enrichment process will be facilitated, as mindfully engaging in domain-related tasks and activities enables individuals to gain more resources (Wayne et al., 2006) and "to develop a better understanding of how to function in that domain as well as what resources may be transferable across domains" (Allen \& Paddock, 2015).

Hypothesis 2: Psychological availability is positively related to work-family enrichment.

\section{Work-Family Enrichment and Thriving at Work}

Thriving is the individual's joint experience of learning and vitality at work (Spreitzer et al., 2005), which reflect the cognitive and affective dimensions of human growth (Porath, Spreitzer, Gibson, \& Garnett, 2012). Learning refers to the individuals' perceptions of continuously improving their knowledge, skills, and/or abilities while performing their job (Dweck, 1986; Elliott \& Dweck, 1988); vitality refers to the positive state of feeling energized and alive when doing one's job and is linked to the perception of having more energy available (Nix, Ryan, Manly, \& Deci, 1999). Although thriving is an emerging concept in management research, we are not aware of any empirical studies that examine the relationship between work-family enrichment and thriving. In this research, we hypothesize that work-family enrichment is likely to augment an individual's sense of thriving at work. Notably, we decided to focus solely on work-family enrichment (rather than on family-work enrichment), because prior research found that the positive effects of work-family enrichment are primarily manifested in the originating role domain (Carlson, Hunter, Ferguson, \& Whitten, 2014; Crain \& Hammer, 2013). Work-family enrichment theorists posit that resources acquired at work, or in other domains such as the family or the community, can be transferred back and forth across domains and used to improve the individual's system functioning and overall quality of life (Greenhaus \& Powell, 2006; Wayne et al., 2007). Here, we suggest that the experience of work-family enrichment and the subsequent gain of personal and contextual resources make individuals more emotionally and intellectually capable of accommodating multiple life stressors and ultimately thrive (Carmeli \& Russo, in press; Halbesleben, Neveu, Paustian-Underdahl, \& Westman, 2014; ten Brummelhuis \& Bakker, 2012). Specifically, we suggest that vitality can be enhanced through work-family enrichment because experiencing synergistic combinations between work and family roles has been shown to multiply rather than deplete individuals' energy (Rothbard, 2001). When 
employees experience work-family enrichment, they feel that they have energy available to devote to other domains (Greenhaus \& Powell, 2006), which is critical to enhance vitality (Nix et al., 1999). Learning can also be enhanced, because the greater the personal and contextual resources individuals gain at work are, the greater their capacity for investing in further development and learning activities will be. This is consistent with recent research showing that work-family enrichment is associated with proactive behaviors, resilience, persistence in goal striving, and job effort (Ruderman, Ohlott, Panzer, \& King, 2002; Russo, 2015; Wayne, Musisca, \& Fleeson, 2004). Notably, Carmeli and Russo (in press) argued that work-family enrichment also manifests in capital gains - for instance through the expansion of an individual's social network - which can be realized in greater learning capacities, as connections are key for accumulating new knowledge (Spreitzer et al., 2005).

Hypothesis 3: Work-family enrichment is positively associated with individual thriving at work.

Finally, we posit that psychological availability and work-family enrichment serially mediate the relationship between FSSB and thriving. Our reasoning builds on the assumption that thriving is a psychological state that can be influenced by situational mechanisms (Spreitzer et al., 2005), such as through the exposure to a favorable environment containing enabling social structures, resources, and/or positive relationships (Hedström \& Swedberg, 1998). We suggest that FSSB, psychological availability, and work-family enrichment represent critical situational resources and mechanisms that can promote greater thriving. FSSB is important for thriving in general, and for learning in particular, as learning does not occur in isolation but is cultivated through social interactions, particularly in the context of supportive leadership (Paterson, Luthans, \& Jeung, 2014). The presence of supportive leadership creates a safe and meaningful climate (Paterson et al., 2014; Vinarski-Peretz \& Carmeli, 2011) that can stimulate social learning (Kwan, 2014). Psychological availability is important, as it manifests in a positive mental state in which individuals are fully accessible to their roles, others, and themselves (Kahn, 2001). This is critical to enhancing the perception of having energy available (Russo, Shteigman, \& Carmeli, in press) and to experiencing positive emotions (Spreitzer et al., 2005) that can expand one's learning capacities (Fredrickson, 2001). Furthermore, we suggest that psychological availability is an important personal resource that facilitates the work-family enrichment process, as it is a psychological condition that sustains and favors the mobilization of other resources and a more effective transfer of resources across domains (Allen \& Paddock, 2015). For instance, psychological availability has been shown to increase individual focus and engagement in domain-related tasks and activities (Kahn, 1990; Vinarski-Peretz \& Carmeli, 2011), which are critical conditions to experiencing greater work-family enrichment (Allen \& Paddock, 2015; Wayne et al., 2007). Finally, as previously mentioned, we believe that work-family enrichment is crucial to promote greater thriving, as it is a generative process that favors the endogenous development of resources, including knowledge, positive affect, and networks (Carmeli \& Russo, in press), which can engender a sense of thriving, as these resources favor the undertaking of proactive behaviors and self-development initiatives (Spreitzer et al., 2005).

Hypothesis 4: Psychological availability and work-family enrichment serially mediate the relationship between FSSB and individual thriving at work. 


\section{The Moderating Role of the Need for Caring}

We have argued that the relationship between FSSB and thriving at work is serially mediated by psychological availability and work-family enrichment. However, drawing on the RGD framework (Wayne et al., 2007) and self-determination theory (Deci \& Ryan, 1985), we suggest that the individual need for caring can influence the strength of FSSB effects. The RGD framework assumes that personal characteristics can influence the work-family enrichment process because they affect the individual's ability to experience positive spillovers, engage in developmental activities, and gain valuable assets in each domain (Wayne et al., 2007). An example of a personal characteristic that influences the work-family enrichment process is work identity, which reflects the importance individuals place on their work to inform their self-identity (Aryee \& Luk, 1996). Wayne et al. (2006) found that employees with a high work identity experience greater work-family enrichment, as they invest more in work-related activities than individuals with a low work identity. This greater investment helps them to enjoy their daily work experiences more and consequently to gain more resources (Wayne et al., 2006).

Self-determination theory posits that individuals have a set of basic psychological needsnamely, competence, autonomy, and relatedness - that, once satisfied, enable individuals to experience better functioning, self-development, growth, and vitality (Deci \& Ryan, 2008; Nix et al., 1999; Warner \& Hausdorf, 2009). Notably, researchers found these basic needs to be universal and their satisfaction to predict psychological well-being in numerous countries (Deci \& Ryan, 2008). In this paper, we suggest that an individual's need for caring can represent a basic psychological need, because similar to the need for relatedness, it captures an individual's desire to connect with and be cared for by others. As such, we expect it can ensure optimal individual functioning and greater thriving once fulfilled. Consistently, we expect that the individual's need for caring moderates the serial-mediated relationships between FSSB and thriving via psychological availability and work-family enrichment. Previous research has shown that employees tend to personify their organization through the figure of their supervisor, such that they develop the perception of being cared for by their organizations when their supervisor provides them with caring behaviors (House, 1981; Kahn, 1993). Thus, we expect FSSB to play a critical role in fulfilling the individual's need for caring. However, like the needs for competence, autonomy, and relatedness (Deci \& Ryan, 2008), we believe that individuals vary in their level of need for caring depending on their particular disposition and/or stage of life (i.e., when they are coping with life events that require more care, support, and empathy from others, such as the birth of a child or when they are navigating an important career transition). Unlike employees with a low need for caring, who may be unresponsive toward the presence of a family supportive supervisor, we believe that the positive effects of FSSB can be amplified for employees with a high need for caring, as they can judge the resources provided by their supervisors as critical to fulfill their actual needs. This is in line with the basic tenets of work-family enrichment research that suggest that resources gained in one domain are more likely to enhance functioning when they are consistent with the actual needs perceived by an individual (Greenhaus \& Powell, 2006). Accordingly, we believe that FSSB will be perceived as more important and beneficial by employees in the high need for caring condition, resulting in stronger positive effects on individual thriving at work through psychological availability and work-family enrichment. 
Hypothesis 5: Need for caring will moderate the strength of the mediated relationship between FSSB and thriving at work via psychological availability and work-family enrichment, such that the serial mediation will be stronger in the high need for caring versus the low need for caring condition.

\section{Study 1}

\section{Method}

Data and procedures. Study 1 was carried out in Italy. There was a planned 6-month time lag between the first (Time 1, July 2013) and the second (Time 2, January 2014) wave, which is considered appropriate for longitudinal studies in work-family studies (Matthews, Wayne, \& Ford, 2014). The authors personally contacted the Italian Management Association asking for authorization to contact some of their affiliated managers. Ten managers showed interest in the research project and invited employees working in their companies to join the research. Then, following the principles of snowball sampling (Biernacki \& Waldorf, 1981), we asked the interested participants to recommend other participants. The prerequisites for inclusion in the final sample were (a) having a full-time job and (b) living with a cohabitating partner and/ or having at least one child to care for at home. A total of 333 employees responded at Time 1 to the survey, which contained demographic questions and the scales to measure FSSB and psychological availability. Six months later, respondents were invited to complete a second survey containing the scales to measure the other study's variables. A total of 191 employees completed the survey at Time 2. Thirty-five respondents were excluded from the sample because they did not meet the study requirements. The final sample was composed of 156 participants, for a response rate of $46.8 \%$. Among the respondents, $44 \%$ were female, with an average age of 44.3 years $(S D=6.44)$. The average number of children was $1.47(S D=$ $0.91)$, the average tenure was 12.69 years $(S D=7.89)$, the average number of working hours per week was $42.55(S D=10.38)$, and $69 \%$ were employed in the private sector. Respondents represented a variety of industries, including health care (27\%), education (24\%), trade (9\%), consulting (7\%), and IT (6\%).

Measures. The scales were administered to the participants in Italian. We followed the back-translation procedure recommended by Brislin (1980) to translate the scales from English to Italian.

FSSB. FSSB was measured at Time 1 on a 14-item scale developed by Hammer et al. (2009). Respondents were asked to indicate to what extent their supervisor was supportive with regard to their work-family problems. A sample item is "My supervisor is willing to listen to my problems in juggling work and non-work life" (emotional support). The Cronbach's alpha was .95 .

Psychological availability. Psychological availability was measured at Time 1 on a fiveitem scale developed by May, Gilson, and Harter (2004). Respondents were asked to indicate to what extent they were confident in their ability to address the competing demands of work and family roles. A sample item is "I am confident in my ability to handle competing demands." The Cronbach's alpha was .85. 
Work-family enrichment. Work-family enrichment was measured at Time 2 on a nineitem scale developed by Carlson, Kacmar, Wayne, and Grzywacz (2006). Respondents were asked to indicate how much their work experiences contributed in enhancing the functioning of their family life. A sample item is "My involvement in my work helps me acquire skills that help me to be a better family member." The Cronbach's alpha was .91.

Thriving at work. Thriving at work was measured at Time 2 on two scales that assess the individual's learning capacity and vitality at work. Learning was measured with a threeitem scale developed by Carmeli and Spreitzer (2009). A sample item is "To what extent do you learn new things at work?" Vitality was measured on an eight-item scale developed by Atwater and Carmeli (2009). A sample item is "I feel active and energetic at work." Results of an exploratory factor analysis (EFA) showed that all items pertaining to thriving loaded onto two factors. The first factor consisted of the learning items, with an eigenvalue of 4.78 , accounting for $47.88 \%$ of the variance and having factor loadings ranging from .78 to .88 . The second factor consisted of the vitality items, with an eigenvalue of 1.55 , accounting for $15.52 \%$ of the variance and having factor loadings ranging from .70 to .80 . Following recent work (Carmeli \& Spreitzer, 2009), we computed the measure of thriving by calculating the average score of the two subscales measuring vitality and learning. The Cronbach's alpha was .88 .

Need for caring. Need for caring was measured at Time 2 with five items developed by the authors that drew on the available literature (Kahn, 1993). The five items were as follows: "I like being close to others and feeling that they care for me"; "I find it very satisfying when others convey caring when they interact with me"; "Just being around others who care for me is valuable to me"; "It is meaningful to me when others care for me"; and "One of the most significant things for me is to know that others care for me." The Cronbach's alpha for the scale was .88. We conducted an EFA to test the construct validity. The results indicate that the five "need for caring" items loaded strongly on the "need for caring" factor. The eigenvalue was 3.416 and explained $68.32 \%$ of the variance. Factor loadings for this factor ranged from .78 to .85 .

Control variables. Consistent with previous research showing that demographics can influence individuals' needs (Bagger \& Li, 2014), we included age (in years) and gender as control variables. Furthermore, we also controlled for tenure with the organization (in years).

\section{Results}

The descriptive statistics and correlations for all the variables are displayed in Table 1. In line with longitudinal research (Matthews, Wayne et al., 2014), we conducted a series of $t$ tests on the demographic variables, FSSB and psychological availability (all the variables measured at Time 1), to control for attrition sample bias. Mean differences were calculated between two groups: (a) the final sample $(n=156)$ and (b) respondents who participated only at Time $1(n=127)$. No group differences were found in terms of gender, age, organizational tenure, marital status, education, type of employment (full-time vs. part-time), FSSB, or psychological availability. Based on these results, we concluded that attrition did not create any significant bias. 


\section{Table 1}

Means, Standard Deviations, and Correlations for Study 1 and Study 2

\begin{tabular}{|c|c|c|c|c|c|c|c|c|c|c|c|c|c|}
\hline & & \multicolumn{2}{|c|}{ Study 1} & \multicolumn{2}{|c|}{ Study 2} & \multirow[b]{2}{*}{1} & \multirow[b]{2}{*}{2} & \multirow[b]{2}{*}{3} & \multirow[b]{2}{*}{4} & \multirow[b]{2}{*}{5} & \multirow[b]{2}{*}{6} & \multirow[b]{2}{*}{7} & \multirow[b]{2}{*}{8} \\
\hline & & $M$ & $S D$ & $M$ & $S D$ & & & & & & & & \\
\hline 1. & Age & 44.33 & 6.44 & 35.15 & 7.28 & - & -.01 & $.52 * *$ & $-.15^{*}$ & -.10 & -.12 & -.10 & -.09 \\
\hline 2. & Gender & - & - & - & - & $-.15 * *$ & - & $.24 * *$ & .11 & -.03 & .10 & $.19^{*}$ & .07 \\
\hline 3. & $\begin{array}{l}\text { Organizational } \\
\text { tenure }\end{array}$ & 12.69 & 7.89 & 9.65 & 6.28 & $.75^{* *}$ & $-.14 * *$ & - & -.01 & $-.17^{*}$ & -.02 & -.02 & -.02 \\
\hline 4. & FSSB & 3.29 & 0.92 & 3.71 & 0.66 & $-.19 * *$ & .04 & $-.19 * *$ & - & .10 & $.39 * *$ & -.05 & $.42 * *$ \\
\hline 5. & $\begin{array}{l}\text { Psychological } \\
\text { availability }\end{array}$ & 3.92 & 0.50 & 3.98 & 0.43 & -.07 & -.01 & $-.08^{*}$ & $.50^{* *}$ & - & $.28 * *$ & -.03 & $.38 * *$ \\
\hline 6. & $\begin{array}{l}\text { Work-family } \\
\text { Enrichment }\end{array}$ & 3.31 & 0.69 & 3.91 & 0.55 & -.02 & -.07 & -.07 & $.51^{* *}$ & $.49 * *$ & - & .13 & $.63 * *$ \\
\hline 7. & $\begin{array}{l}\text { Need for } \\
\text { caring }\end{array}$ & 3.65 & 0.60 & 4.07 & 0.42 & -.03 & .06 & -.08 & $.30 * *$ & $.32 * *$ & $.46^{* *}$ & - & .04 \\
\hline 8. & Thriving & 3.79 & 0.60 & 3.98 & 0.47 & -.02 & -.07 & $-.12 *$ & $.47 * *$ & $.49 * *$ & $.67 * *$ & $.50 * *$ & - \\
\hline
\end{tabular}

Note: Values above the diagonal are for Study $1(n=156)$; values below the diagonal are for Study $2(n=356)$.

$* p<.05$.

$* * p<.01$.

We conducted a confirmatory factor analysis on FSSB, psychological availability, workfamily enrichment, need for caring, and thriving to verify their independent nature. The fivefactor model $\left[\chi^{2}=2,322.22, d f=1293\right.$, comparative fit index $(\mathrm{CFI})=.90$, incremental fit index $(\mathrm{IFI})=.90$, root mean square of error approximation $(\mathrm{RMSEA})=.05$ ] was superior to the two four-factor models considered, where we combined psychological availability and work-family enrichment $\left(\chi^{2}=2,803.40, d f=1,297, \mathrm{CFI}=.79, \mathrm{IFI}=.73, \mathrm{RMSEA}=.08\right)$ and work-family enrichment and thriving, respectively $\left(\chi^{2}=3,524.19, d f=1,319, \mathrm{CFI}=.69\right.$, IFI $=.69$, RMSEA $=.10)$, and to the one-factor model where all the items were loaded onto one single factor $\left(\chi^{2}=6,073.68, d f=1,325, \mathrm{CFI}=.34\right.$, IFI $\left.=.34, \mathrm{RMSEA}=.15\right)$.

All hypotheses were tested using a conditional process analysis program, PROCESS, which computes ordinary least square regressions to test for direct and indirect effects (Hayes \& Preacher, 2013). We employed PROCESS Model 6 (serial mediation) to estimate regression coefficients and follow-up bootstrap analyses with 5,000 bootstrap samples to estimate $95 \%$ bias-corrected confidence intervals for specific and total indirect effects. Serial mediation assumes "a causal chain linking the mediators, with a specified direction of causal flow" (Hayes, 2012: 14). Accordingly, individual thriving was entered as the outcome variable, FSSB as the predictor variable, and psychological availability and work-family enrichment as the two serial mediators in this causal order: FSSB $\rightarrow$ psychological availability $\rightarrow$ work-family enrichment $\rightarrow$ thriving. To test for the presence of moderated serial mediations, we examined whether there was a significant interaction between FSSB and need for caring in predicting psychological availability and work-family enrichment as well as whether the conditional effects of FSSB on thriving, via psychological availability and work-family enrichment, across high, moderate, and low levels of need for caring, were statistically different from zero (i.e., the estimated confidence interval excluded zero). This latter condition is crucial to demonstrate whether the strength of the serial-mediated relationship differs across participants who present a high or a low need for caring. Finally, following Hayes's (2015) recommendations, we computed an index of moderated mediation, which enables quantification of the weight and size of 


\section{Table 2}

Unstandardized Regression Coefficients With Confidence Intervals Estimating Psychological Availability, Work-Family Enrichment, and Individual Thriving (Study 1)

\begin{tabular}{|c|c|c|c|c|c|c|}
\hline \multirow[b]{2}{*}{ Variables } & \multicolumn{2}{|c|}{$\begin{array}{l}\text { Psychological } \\
\text { Availability }\end{array}$} & \multicolumn{2}{|c|}{$\begin{array}{l}\text { Work-Family } \\
\text { Enrichment }\end{array}$} & \multicolumn{2}{|c|}{ Thriving } \\
\hline & Coeff. & $95 \% \mathrm{CI}$ & Coeff. & $95 \% \mathrm{CI}$ & Coeff. & $95 \% \mathrm{CI}$ \\
\hline Age & -.01 & $-.01, .01$ & -.01 & $-.01, .01$ & .01 & $-.01, .01$ \\
\hline Gender & .01 & $-.16, .17$ & .03 & $-.16, .23$ & .01 & $-.14, .16$ \\
\hline Organizational tenure & -.01 & $-.02, .01$ & .01 & $-.01, .02$ & .01 & $-.01, .01$ \\
\hline FSSB & .03 & $-.05, .12$ & $.21 * *$ & $.10, .31$ & .14 & $.05, .22$ \\
\hline Need for caring & -.02 & $-.16, .10$ & $.23 * *$ & $.07, .39$ & -.01 & $-.14, .11$ \\
\hline Psychological availability & & & $.30 * *$ & $.11, .49$ & $.26 * *$ & $.11, .41$ \\
\hline Work-family enrichment & & & & & $.44 * *$ & $.32, .57$ \\
\hline \multirow[t]{4}{*}{ FSSB $\times$ Need for Caring } & .03 & $-.08, .14$ & $0.28 * *$ & $.14, .42$ & -.04 & $-.16, .06$ \\
\hline & \multicolumn{2}{|c|}{$R^{2}=.04$} & \multicolumn{2}{|c|}{$R^{2}=.31$} & \multicolumn{2}{|c|}{$R^{2}=.47$} \\
\hline & \multicolumn{2}{|c|}{$F(6,000)=1.13$} & \multicolumn{2}{|c|}{$F(7,000)=9.39 * *$} & \multicolumn{2}{|c|}{$F(8,000)=16.42^{* *}$} \\
\hline & \multicolumn{2}{|c|}{ Effect } & \multicolumn{2}{|c|}{ Boot $S E$} & $p$ & CI \\
\hline \multicolumn{7}{|c|}{ Direct effect of FSSB on thriving } \\
\hline \multirow[t]{2}{*}{ FSSB } & \multicolumn{2}{|c|}{.14} & \multicolumn{2}{|c|}{.04} & .01 & $.05, .22$ \\
\hline & & & \multicolumn{2}{|c|}{ Effect } & Boot $S E$ & $\mathrm{CI}$ \\
\hline \multicolumn{7}{|c|}{ Indirect effect of FSSB on thriving } \\
\hline \multicolumn{3}{|c|}{ Total } & \multicolumn{2}{|c|}{.11} & .03 & $.04, .19$ \\
\hline \multicolumn{3}{|c|}{ Model 1: Through psychological availability alone } & \multicolumn{2}{|c|}{.01} & .01 & $-.01, .04$ \\
\hline \multicolumn{3}{|c|}{ Model 2: Through work-family enrichment alone } & \multicolumn{2}{|c|}{.09} & .03 & $.04, .16$ \\
\hline \multicolumn{3}{|c|}{$\begin{array}{l}\text { Model 3: Through psychological availability and } \\
\text { work-family enrichment }\end{array}$} & \multicolumn{2}{|c|}{.01} & .01 & $-.01, .02$ \\
\hline
\end{tabular}

Note: The number of bootstrap samples for the bias-corrected interval is 5,000. Variables involved in the product term were mean-centered. $\mathrm{CI}=$ Confidence Interval.

$* p<.05$.

$* * p<.01$.

the association between the moderator and the indirect effect. This index is particularly important because a significant interaction between a predictor and a moderator does not automatically indicate the presence of moderation (Hayes, 2015).

The estimated regression coefficients are displayed in Table 2. FSSB was not significantly associated with psychological availability $(b=.03, p>.10)$, whereas psychological availability was significantly associated with work-family enrichment $(b=.30, p<.05)$, and work-family enrichment was significantly associated with thriving $(b=.44, p<.01)$ in the expected direction. This finding does not support Hypothesis 1 (linking FSSB to psychological availability), but it does support Hypothesis 2 (linking psychological availability to work-family enrichment) and 
Hypothesis 3 (linking work-family enrichment to thriving). To test for H4, predicting the serial mediation, we calculated specific and total indirect effects of FSSB to thriving through at least one mediator and through the two serial mediators. Model 1 tested whether only psychological availability mediated the relationship between FSSB and thriving, Model 2 tested whether only work-family enrichment mediated the relationship between FSSB and thriving, and Model 3 tested the hypothesized serial-mediated model. The total indirect effect (.11) was statistically different from zero with $95 \%$ confidence (.04 to .19). The specific indirect effect of FSSB on thriving via psychological availability (.01) was not statistically different from zero with $95 \%$ confidence (-.01 to .04), whereas the specific indirect effect of FSSB on thriving via workfamily enrichment (.09) was statistically different from zero with $95 \%$ confidence (.04 to .16). In contrast to what we hypothesized, the specific indirect effect of FSSB on thriving via psychological availability and work-family enrichment (.01) was not statistically different from zero with $95 \%$ confidence ( -.01 to .02). To test Hypothesis 5, predicting the moderating role of need for caring, we computed the index of moderated mediation that is quantified as the product of the function linking FSSB to psychological availability, the effect of psychological availability on work-family enrichment, and the effect of work-family enrichment on individual thriving (for details on how to calculate the index of moderated mediation, see Hayes, 2015). The results indicate that the index of moderated mediation for the specific indirect effect pertaining to the serial mediation (.004) was not statistically different from zero with $95 \%$ confidence ( -.0005 to .0108 ), meaning that no moderation of the specific indirect effect through psychological availability and work-family enrichment by need for caring was plausible. The index of moderated mediation for Model 2, pertaining to the specific indirect effect through work-family enrichment alone (.12), was statistically different from zero with $95 \%$ confidence (.05 to .23 ), so we can fairly confidently say that this specific indirect effect depends on need for caring.

Supplementary analysis. One problem in interpreting the results of this study concerns the direction of causality between the study's variables. To ascertain the validity of the serial causal chain hypothesized in the research model, we tested three different alternative models: one in which FSSB predicted thriving via work-family enrichment and psychological availability (inverted causal order of the two serial mediators) at different levels of need for caring, one in which FSSB predicted work-family enrichment via psychological availability and thriving at different levels of need for caring, and one in which FSSB predicted work-family enrichment via thriving and psychological availability at different levels of need for caring. The results show that the index of moderated mediation related to the first alternative causal model (FSSB $\rightarrow$ workfamily enrichment $\rightarrow$ psychological availability $\rightarrow$ thriving) was not statistically significant, as the confidence interval included the zero (index $=.012,95 \%$ bootstrap confidence interval $=$ -.004 to .02). Similar results were found for the index of moderated mediation related to the second, FSSB $\rightarrow$ psychological availability $\rightarrow$ thriving $\rightarrow$ work-family enrichment (index $=.006$, $95 \%$ bootstrap confidence interval $=-.01$ to .02 ), and third, FSSB $\rightarrow$ thriving $\rightarrow$ psychological availability $\rightarrow$ work-family enrichment (index $=.05,95 \%$ bootstrap confidence interval $=-.004$ to .007), alternative causal models. Full results are available from the corresponding author.

\section{Discussion}

The results of Study 1 suggest that work-family enrichment is the primary mediator of the relationship between FSSB and individual thriving and that this indirect relationship is 
significant only for employees experiencing a high need for caring. Although this finding is different from what we hypothesized, these results are worth noting from a theoretical and practical point of view. Theoretically, these results are important, as this is, to our knowledge, the first study that links FSSB to thriving. The results confirm that work-family enrichment is a fundamental mediating mechanism linking workplace resources (FSSB) to positive work-related outcomes (thriving) (Crain \& Hammer, 2013; Lapierre et al., 2008). The results also demonstrate that individuals with a high need for caring are more responsive to FSSB and work-family enrichment than those with a low need for caring. From a practical point of view, these results are important, as they demonstrate that FSSB does not have the same importance for all employees indiscriminately. This finding can help supervisors to better target their supportive behaviors in order to maximize the payoff from their effort (Bagger \& $\mathrm{Li}, 2014)$. We believe that examining mechanisms and conditions in which employees can better manage their work-family interface is crucial in today's Italian work environment, where, due to the economic crisis, there is limited work-family organizational support, as recently indicated by Riva (2015), who found that only 13\% of union agreements ratified in Italian companies include work-family supportive policies. Thus, the informal support provided by the supervisor may compensate for the lack of formal company support and play a critical role in helping employees to experience greater work-family enrichment and, ultimately, to thrive.

\section{Study 2}

Study 2 was designed to accomplish three main goals. First, although Study 1 helped to clarify the indirect relationship between FSSB and thriving, it did not probe the presence of a serial mediation, as the results demonstrate that only work-family enrichment mediated the relationship between FSSB and thriving. This is in line with prior research that has established a direct link between FSSB and work-family enrichment (Hammer et al., 2009; Lu, Siu, Spector, \& Shi, 2009; Odle-Dusseau et al., 2012). However, we believe that it is important to examine a more complex model that includes psychological availability as a mediator of the relationship between FSSB and work-family enrichment, as this would enable us to also provide a more accurate understanding of what individual and organizational factors can facilitate the work-family enrichment process, which is a question that has received little attention in prior research (Greenhaus \& Singh, 2007; Kim \& Las Heras, 2012).

Second, although Study 1 extends prior literature by examining the consequences of FSSB in a non-U.S. country (Las Heras et al., 2015), Italy belongs to the Western region of the world and presents similar cultural characteristics to those of the United States regarding leadership traits that can influence the availability of and access to work-family supportive resources at work (Poelmans et al., 2003; Spector et al., 2004). Indeed, Italy and the United States have similar scores in the GLOBE project with regard to gender egalitarianism and individualism/collectivism (House, Hanges, Javidan, Dorfman, \& Gupta, 2004). China, on the other hand, has significant differences from Italy concerning these cultural dimensions, in particular a higher score for collectivism and a lower score for gender egalitarianism (House et al., 2004). Therefore, we contend that examining the proximal and distal consequences of FSSB in China is important to provide a more complete understanding of FSSB effects in different regions of the world. 
Third, instead of using a snowball sampling technique, which can create problems of representativeness due to the fact that respondents tend to identify other participants similar to themselves (Saunders, Lewis, \& Thornhill, 2003), we decided to recruit a Chinese market study company to collect data using a representative sample of the working population at the community level (i.e., qu xian in Chinese, a subdivision of a prefecture-level municipality), with predetermined quotas based on sex, age, occupation, and employment status drawn from China's 2010 census. This strategy also gave Study 2 a broader range than Study 1 in terms of the level of supportive behaviors provided by supervisors in different organizations (cf. Bagger \& Li, 2014).

\section{Method}

\section{Data and Procedures}

Data were collected in the Beijing, Shanghai, and Guangzhou metropolitan areas of China. The survey administrators began at the first dwelling place from the central north corner of the community and proceeded in a specified direction until the quotas were filled. Questionnaires were distributed to potential participants in each household between 8:00 and 9:30 p.m. The survey administrators collected the questionnaires 2 weeks later. The prerequisites to participate in the survey were the same as in Study 1: (a) to have a full-time job and (b) to live with a cohabitating partner and/or to have at least one child to care for at home. Time 1 was conducted in February 2014, and a total of 1,090 individuals completed the first questionnaire in 47 subprefecture-level communities. Time 2 was conducted in August 2014, and 570 out of the 1,090 individuals in the first wave completed the second questionnaire. A monetary reward (US\$20) was given to all respondents who completed both waves. We excluded 214 participants because they did not meet the criteria (i.e., they were single and did not have children). The final sample consisted of 356 participants, for a response rate of $32.6 \%$. Among the respondents, 54.5\% were female, and age ranged from 20 to $62(M=$ $35.15, S D=7.28)$. Due to China's one-child policy, family size was small; $94.9 \%$ of respondents had only one child. Most of the respondents had at least a secondary school education $(93.3 \%) ; 36 \%$ worked in the public sector, and the rest worked in the private sector in various industries, including manufacturing (42\%), high tech (14\%), agriculture and fishing $(12 \%)$, finance and banking (6\%), and other services $(26 \%)$.

\section{Measures}

We used the same scales as in Study 1. We followed the back-translation procedure recommended by Brislin (1980) to translate the study's scale from English to Chinese. As in Study 1, the results of the EFA for thriving showed that all items pertaining to thriving loaded onto two factors. The first factor consisted of the learning items, with an eigenvalue of 6.02, which accounted for $54.72 \%$ of the variance and had factor loadings ranging from .87 to .89 . The second factor consisted of the three learning items, with an eigenvalue of 1.17 , accounting for $10.64 \%$ of the variance and having factor loadings ranging from .70 to .80 . We then calculated thriving as the average score for the learning and vitality subscales. The Cronbach's alphas were .92 for FSSB, .83 for psychological availability, .91 for work-family enrichment, .80 for need for caring, and .91 for thriving. We controlled for the same variables as in Study 1 - age (in years), gender, and organizational tenure (in years). 
As in Study 1, given that our measure of need for caring was new, we performed an EFA to test the construct validity. The results indicated that the five "need for caring" items loaded strongly on the need for caring factor. The eigenvalue was equal to 2.81 and explained $56.24 \%$ of the variance. Factor loadings for this factor ranged from .75 to .84 . A multigroup CFA analysis was conducted to establish measurement invariance between the Chinese and Italian samples. We first estimated the unconstrained measurement model and then imposed invariance constraints between the two samples. The results indicated that both the unconstrained and the constrained model fit the data relatively well (CFI $=.958$ vs. .953; GFI $=$ .956 vs. .950). The value of the omnibus chi-square test was .069, which argues for noninvariance. Schmitt and Kuljanin (2008) noted that large samples and complex models are highly susceptible to significant changes in the chi-square value. To confirm the measurement invariance of the need for caring, we followed Cheung and Rensvold (2000) by calculating the delta RMSEA, given that this measure is not affected by model complexity (Meade \& Kroustalis, 2006). The model showed measurement equivalence in that the difference in the RMSEA between the constrained and unconstrained models was .008 (.077 vs. .069), which is below the critical value (.10), as established by Cheung and Rensvold (2000). The results of the measurement invariance tests suggest factor validity for the measure of need for caring. Finally, as in Study 1, we conducted a confirmatory factor analysis on FSSB, psychological availability, work-family enrichment, need for caring, and thriving to verify their independent nature. The five-factor model $\left(\chi^{2}=2,984.63, d f=1,293, \mathrm{CFI}=.90, \mathrm{IFI}=.90\right.$, RMSEA $=.04)$ was superior to the two four-factor models considered, where we combined psychological availability and work-family enrichment $\left(\chi^{2}=3,825.23, d f=1,297, \mathrm{CFI}=.85\right.$, IFI $=.85$, RMSEA $=.05)$ and work-family enrichment and thriving, respectively $\left(\chi^{2}=\right.$ $3,707.56, d f=1,319, \mathrm{CFI}=.86$, IFI $=.86$, RMSEA $=.05)$, and it was superior to the onefactor model $\left(\chi^{2}=7,974.99, d f=1,325, \mathrm{CFI}=.61, \mathrm{IFI}=.61, \mathrm{RMSEA}=.09\right)$.

\section{Results}

The descriptive statistics and correlations for all the variables are presented in Table 1. To test for attrition bias in our sample, we performed a series of $t$ tests between two groups on demographic variables and variables assessed at Time 1, namely FSSB and psychological availability: (a) the final sample $(n=356)$ and (b) respondents who participated only at Time $1(n=261)$. No group differences were found in terms of age, gender, number of hours worked per week, FSSB, or psychological availability. Some differences were found in terms of organizational tenure and education. The final sample was composed of a larger proportion of highly educated employees with longer tenure in their organization as compared to respondents who participated only at Time 1. To control for attrition bias, we followed Heckman's (1979) procedure. We first built a logistic regression model to estimate the effects of education and organizational tenure on the dichotomous dependent variable that was created, with 1 representing employees who participated both at Time 1 and Time 2 and 0 representing employees who dropped out of the study after Time 1. Based on the residuals of this logistic regression, we used Heckman's formula to calculate Lee's Lambda, which was afterward included in the regression models as a control variable.

Consistent with Study 1, we employed PROCESS Model 6 to estimate regression coefficients and follow-up bootstrap analyses with 5,000 bootstrap samples to estimate 


\section{Table 3}

Unstandardized Regression Coefficients With Confidence Intervals Estimating Psychological Availability, Work-Family Enrichment, and Individual Thriving (Study 2)

\begin{tabular}{|c|c|c|c|c|c|c|}
\hline \multirow[b]{2}{*}{ Variables } & \multicolumn{2}{|c|}{$\begin{array}{c}\text { Psychological } \\
\text { Availability }\end{array}$} & \multicolumn{2}{|c|}{$\begin{array}{l}\text { Work-Family } \\
\text { Enrichment }\end{array}$} & \multicolumn{2}{|c|}{ Thriving } \\
\hline & Coeff. & $95 \% \mathrm{CI}$ & Coeff. & $95 \% \mathrm{CI}$ & Coeff. & $95 \% \mathrm{CI}$ \\
\hline Age & $.01 *$ & $.01, .20$ & .01 & $-.01, .01$ & .01 & $-.01, .01$ \\
\hline Gender & -.05 & $-.12, .12$ & $-.09 * *$ & $-.18,-.01$ & -.03 & $-.09, .02$ \\
\hline Organizational tenure & $-.01 *$ & $-.02,-.01$ & -.01 & $-.01, .01$ & -.01 & $-.01, .01$ \\
\hline Lambda & -.01 & $-1.06,1.05$ & -.45 & $-1.73, .81$ & .67 & $-.18,1.53$ \\
\hline FSSB & $.27 * *$ & $.21, .33$ & $.25 * *$ & $.18, .33$ & .03 & $-.01, .90$ \\
\hline Need for caring & $.19^{* *}$ & $.10, .28$ & $.40 * *$ & $.29, .51$ & $.18 * *$ & $.10, .26$ \\
\hline Psychological availability & & & $.29 * *$ & $.16, .42$ & $.10^{* *}$ & $.02, .19$ \\
\hline Work-family enrichment & & & & & $.52 * *$ & $.44, .59$ \\
\hline \multirow[t]{4}{*}{ FSSB $\times$ Need for Caring } & $.14 * *$ & $.01, .26$ & $.13^{+}$ & $-.02, .28$ & -.04 & $-.14, .05$ \\
\hline & \multicolumn{2}{|c|}{$R^{2}=.31$} & \multicolumn{2}{|c|}{$R^{2}=.43$} & \multicolumn{2}{|c|}{$R^{2}=.64$} \\
\hline & \multicolumn{2}{|c|}{$F(6,000)=26.52 * *$} & \multicolumn{2}{|c|}{$F(7,000)=37.65 * *$} & \multicolumn{2}{|c|}{$F(8,000)=78.47^{* *}$} \\
\hline & \multicolumn{2}{|c|}{ Effect } & \multicolumn{2}{|c|}{ Boot $S E$} & $p$ & $\mathrm{CI}$ \\
\hline \multicolumn{7}{|c|}{ Direct effect of FSSB on thriving } \\
\hline \multirow[t]{2}{*}{ FSSB } & \multicolumn{2}{|c|}{.03} & \multicolumn{2}{|c|}{.02} & .18 & $-.01, .09$ \\
\hline & & & \multicolumn{2}{|c|}{ Effect } & Boot SE & $\mathrm{CI}$ \\
\hline \multicolumn{7}{|c|}{ Indirect effect of FSSB on thriving } \\
\hline \multicolumn{3}{|c|}{ Total } & \multicolumn{2}{|c|}{.20} & .04 & $.13, .30$ \\
\hline \multicolumn{3}{|c|}{ Model 1: Through psychological availability alone } & \multicolumn{2}{|c|}{.03} & .01 & $.01, .07$ \\
\hline \multicolumn{3}{|c|}{ Model 2: Through work-family enrichment alone } & \multicolumn{2}{|c|}{.13} & .03 & $.07, .22$ \\
\hline \multicolumn{3}{|c|}{$\begin{array}{l}\text { Model 3: Through psychological availability and } \\
\text { work-family enrichment }\end{array}$} & \multicolumn{2}{|c|}{.14} & .01 & $.01, .08$ \\
\hline
\end{tabular}

Note: Number of bootstrap samples for bias corrected interval $=5,000$. Standard errors are in parentheses. Variables involved in the product term were mean centered.

$* p<.05$.

$* * p<.01$.

95\% bias-corrected confidence intervals for specific and total indirect effects. Furthermore, we followed indications by Preacher, Rucker, and Hayes (2007) and Hayes (2015) to ascertain the moderated serial mediation. The estimated regression coefficients are displayed in Table 3. FSSB was significantly associated with psychological availability $(b=.27, p<.01)$, psychological availability was significantly associated with work-family enrichment $(b=.29, p<$ $.01)$, and work-family enrichment was significantly associated with thriving $(b=.52, p<.01)$ in the expected direction. This provides support for Hypothesis 1 (linking FSSB to psychological availability), Hypothesis 2 (linking psychological availability to work-family enrichment), and Hypothesis 3 (linking work-family enrichment to thriving). To test for Hypothesis 4 , predicting the serial mediation, we calculated specific and total indirect effects of FSSB to 
thriving through at least one mediator and through the two serial mediators. Model 1 tested whether only psychological availability mediated the relationship between FSSB and thriving, Model 2 tested whether only work-family enrichment mediated the relationship between FSSB and thriving, and Model 3 tested the full serial-mediated model: FSSB $\rightarrow$ psychological availability $\rightarrow$ work-family enrichment $\rightarrow$ thriving. The total indirect effect (.20) was statistically different from zero with $95 \%$ confidence (.13 to .30). The specific indirect effect of FSSB on thriving via psychological availability (.03) was marginally statistically different from zero with $95 \%$ confidence (.003 to .07), and the specific indirect effect of FSSB on thriving via work-family enrichment (.13) was statistically different from zero with $95 \%$ confidence (.07 to .22). In line with our hypotheses, the specific indirect effect of FSSB on thriving via psychological availability and work-family enrichment (.04) was statistically different from zero with $95 \%$ confidence (.01 to .08). To test Hypothesis 5, predicting the moderating role of need for caring on the serial-mediated relationship between FSSB and thriving, we computed the index of moderated mediation for the specific indirect effects. The results indicate that the index of moderated mediation pertaining to the serial mediation (.06) was statistically different from zero with $95 \%$ confidence (.02 to .08), meaning that moderation of the specific indirect effect through psychological availability and work-family enrichment by need for caring was plausible. The index of moderated mediation for Model 1, pertaining to the specific indirect effect of FSSB on thriving via psychological availability alone (.01), was not statistically different from zero with $95 \%$ confidence (-.01 to .05). The index of moderated mediation pertaining to the specific indirect effect of FSSB on thriving via work-family enrichment alone (.06) was significant with $95 \%$ confidence interval (.01 to .02).

\section{Supplementary Analyses}

As in Study 1, to ascertain the validity of the serial causal model, we tested three alternative models: one in which FSSB predicted thriving via work-family enrichment and psychological availability (inverted causal order of the two serial mediators) at different levels of need for caring, one in which FSSB predicted work-family enrichment via psychological availability and thriving at different levels of need for caring, and one in which FSSB predicted work-family enrichment via thriving and psychological availability at different levels of need for caring. The results show that the index of moderated mediation related to the first alternative causal model (FSSB $\rightarrow$ work-family enrichment $\rightarrow$ psychological availability $\rightarrow$ thriving) was not statistically significant as the confidence interval included the zero (index $=.08,95 \%$ bootstrap confidence interval $=-.03$ to .20 ). Similar results were found for the index of moderated mediation related to the second, FSSB $\rightarrow$ psychological availability $\rightarrow$ thriving $\rightarrow$ work-family enrichment (index $=.01,95 \%$ bootstrap confidence interval $=-.001$ to .05), and third, FSSB $\rightarrow$ thriving $\rightarrow$ psychological availability $\rightarrow$ work-family enrichment (index $=.02,95 \%$ bootstrap confidence interval $=-.11$ to .17 ), alternative causal models. Full results are available from the corresponding author.

\section{Discussion}

Study 2 provided support for the serial indirect effect of FSSB on thriving via psychological availability and work-family enrichment at conditional levels of need for caring. Specifically, the results suggest that the positive effects of FSSB on individual thriving via 
psychological availability and work-family enrichment were stronger when individuals' need for caring was high. This was true also when considering only work-family enrichment as a mediator. The results demonstrate that when resources gained at work matched the individuals' actual needs, they were more likely to produce positive outcomes (Greenhaus \& Powell, 2006). Differing from Study 1, the results demonstrate that psychological availability mediated the relationship between FSSB and work-family enrichment. This is theoretically important given that prior studies have mostly examined a direct relationship between FSSB and work-family enrichment (e.g., Odle-Desseau et al., 2012) while paying only limited attention to underlying mechanisms connecting workplace resources to work-family enrichment (Greenhaus \& Singh, 2007; Kim \& Las Heras, 2012). We provided preliminary evidence that psychological availability is a critical individual resource that enables employees to better translate the family support provided by the supervisor into greater work-family enrichment. This is likely to happen because when employees experience psychological availability, they feel more ready to engage in what they are doing and become more focused on domain-related activities and tasks (Kahn, 1990), which are critical behaviors to experience work-family enrichment (Wayne et al., 2007). This result also provides indirect support to the nascent literature on the relationship between mindfulness and work-family constructs (Allen \& Paddock, 2015), as the results empirically demonstrate the validity of one of the fundamental tenets of this stream of research - that is, that being mindful enhances the individual's capacity to gain valuable resources and helps the individual to better understand what resources can be transferred back and forth across domains and how this process functions (Allen \& Paddock, 2015).

\section{General Discussion}

In the present article, we examined the serial-mediated relationship between FSSB and thriving at work via psychological availability and work-family enrichment at conditional levels of need for caring. The findings of the two studies conducted in Italy (Study 1) and China (Study 2) supported the serial-mediated effect of FSSB on thriving via psychological availability and work-family enrichment in China at conditional levels of need for caring, whereas in Italy the indirect relationship between FSSB and thriving at conditional levels of need for caring was mediated only by work-family enrichment. Since a serial mediation assumes a specified direction of causality that is established by researchers (Hayes, 2012), we ran a series of supplementary models with alternative causal relationships between the study's variables. The results lend some additional support to the theorized causal direction of the research model since the supplementary causal models tested were not statistically significant.

This study extends the growing literature on FSSB in three important ways. First, our results demonstrate that the presence of a family supportive supervisor creates an enabling work context in which employees feel more psychologically available, experience greater work-family enrichment, and develop a heightened sense of thriving at work (Study 2). This research enables us to deepen our knowledge about the relationship between work-family interface and thriving (Spreitzer, 2013) and to provide a more comprehensive analysis of the process behind the positive effects of FSSB (Straub, 2012). A focus on thriving as an outcome of FSSB is important, considering that thriving is key in mitigating the negative effects 
of stress (Maslach, 2003), increasing individuals' and organizations' performance (Porath et al., 2012) and helping employees to better navigate their careers in turbulent modern times (Hall, 1998). This study demonstrates that FSSB, psychological availability, and work-family enrichment are meaningful for developing a sense of thriving in the workplace. This conclusion is consistent with previous research (Paterson et al., 2014) pointing to heedful relationships with supervisors as crucial for fostering individual learning and further expands on studies indicating the importance of psychological availability and work-family enrichment in increasing positive energy at work (Russo et al., in press), high-quality interactions (Danner-Vlaardingerbroek, Kluwer, van Steenbergen, \& van der Lippe, 2013), and positive mood (Carlson et al., 2014). Thus, our research extends this line of theorizing about the conditions and process by which employees can achieve greater work-family enrichment and thrive in the workplace (Carmeli \& Russo, in press).

Second, this study demonstrates that the indirect relationship between FSSB and thriving was stronger for employees in the high need for caring condition. These results have important theoretical implications, as they are consistent with previous findings showing that FSSB is more salient and beneficial for employees who have objective care responsibilities (Matthews, Mills et al., 2014); moreover, the results extend this line of theorizing by highlighting the importance of subjective caring needs in the FSSB outcome process. This is important, as past research has rarely considered individual factors as moderators of the effects of FSSB, focusing more on organizational and contextual factors (Bagger \& Li, 2014; Hammer et al., 2011; Matthews, Mills et al., 2014). Notably, these results also have important implications for research on enrichment, as they provide empirical evidence for one of the basic tenets of work-family enrichment theory, suggesting that psychological dynamics can influence the extent to which individuals experience work-family enrichment (Greenhaus \& Powell, 2006). Greenhaus and Powell (2006) theorized that the resources gained in one role are more likely to promote performance improvements in another (e.g., greater workfamily enrichment) when they are consistent with the actual needs perceived by a given employee. Accordingly, in the present study, we found that FSSB tends to be perceived as more beneficial by employees with a higher need for caring, because FSSB contributes to fulfilling their actual needs.

Third, we found that FSSB promotes greater thriving for employees in both Italy and China. This finding has important theoretical implications for work-family and thriving research, as it both responds to recent calls for further research on the consequences of FSSB in non-U.S. countries (Las Heras et al., 2015; Matthews, Mills et al., 2014) and extends research on thriving by examining how individuals thrive in different countries. However, we found that the process conducive to positive effects of FSSB on thriving was different in Italy than in China, with psychological availability and work-family enrichment significantly mediating the relationship between FSSB and thriving in China, whereas in Italy psychological availability was not significantly associated with FSSB. A possible explanation for this result may be related to the different factors upon which Chinese and Italian employees gauge the quality of their employment relationship. Chinese employees tend to rely upon person-specific relationships to gauge the quality of the employment relationship, with particular attention to the relationship with their immediate supervisor, on whom they depend to give them access to the resources they need (Pearce, Branyiczki, \& Bakacsi, 1994). On the other hand, employees in Western countries, like Italian employees, tend to gauge the quality 
of their employment relationship based upon a broader kind of "organizational thinking" (Hui, Lee, \& Rousseau, 2004); that is, the employment relationship is conceived as a broader bond with the whole organization. This means that additional factors such as organizational policies, rules, and structure, in addition to relationships with the supervisors, are key in shaping employees' cognitive, affective, and behavioral reactions at work. Moreover, we believe that the employees' different expectations to receive assistance at work concerning their family-related problems can influence the reactions towards FSSB. A recent study by Chen (2006) indicates that only $31 \%$ of employees in China expect to receive help at work for their family-related problems, as they consider sacrifices in family life to be inevitable for ensuring a stable financial position for themselves and their families. On the other hand, Italian employees develop high expectations of receiving aid in handling work-family balance issues even in the early stages of their careers (Buonocore, Russo, \& Ferrara, 2015). Thus, Chinese employees might perceive the presence of a family supportive supervisor as something of particular value, whereas Italian employees may view it more as something to which they are entitled. Because of this, and consistent with prior research that has demonstrated the value of examining FSSB through the social exchange relationship lens (Bagger \& Li, 2014; Hammer et al., 2015), we believe that the exposure to FSSB can contribute more to signaling a high-quality employment relationship for Chinese employees than for Italian ones. This reasoning can help to explain the significant positive relationship between FSSB and psychological availability in China, as the high-quality relationship with the supervisor can lead employees to engage with more intensity, attention, and motivation at work (i.e., with greater psychological availability) in order to reciprocate the positive treatment received by their supervisor (Hammer et al., 2015).

\section{Practical Implications}

Our results provide evidence that FSSB is crucial to experiencing greater thriving at work. FSSB can contribute to making employees more resourceful and thereby more capable of successfully accommodating work and family commitments with positive consequences for their sense of thriving. Given that FSSB is a newly introduced concept in work-family research (Hammer et al., 2011), supervisors may not be sufficiently prepared to engage in family supportive behaviors at work (Lirio, Lee, Williams, Haugen, \& Kossek, 2008). Therefore, a fundamental intervention to promote in organizations would be to provide supervisors with specific FSSB training (Hammer et al., in press). Recent research (Hammer et al., 2011) has shown the usefulness of training in (a) enhancing supervisors' awareness about the benefits of FSSB, (b) developing FSSB skills, and (c) tracking supervisors' supportive behaviors. Sample topics generally covered in FSSB training include a description of the four FSSB dimensions, a depiction of the benefits associated with FSSB, an examination of the different foci of support (e.g., including work, family, and personal support), and a reflection on the importance for supervisors to model exemplary behaviors (Hammer et al., 2015).

Our results also indicate that employees who have a higher need for caring are more sensitive to FSSB. This has important practical implications in today's frantic world, where managers find themselves under intense work pressure and have limited resources available (Bagger \& Li, 2014). Our results can help supervisors to target the recipients who will be most positively affected by FSSB in order to enhance the likelihood that their efforts will 
generate positive outcomes. For example, the results demonstrate that employees with a low need for caring are less sensitive to the presence of supervisors' family supportive behaviors, which can nullify the supervisors' efforts and waste important resources. Therefore, we suggest that supervisors attempt to identify, through formal and informal interviews and/or periodic surveys, which employees are most in need of support and direct their FSSB first to those employees.

\section{Limitations and Future Research}

This study has several limitations. Although we collected data over time with a 6-month time lag, which should be sufficient to reduce common method variance (Podsakoff, MacKenzie, \& Podsakoff, 2012), and tested alternative models that provided some additional support to the theorized serial mediation model, the lack of an autoregressive research design (in which data on all variables are collected at all points in time) calls for caution regarding the causal ordering of the study's variables. We thus recommend that future researchers seek to refine and strengthen our methodology, for example by collecting data on the variables at all points in time in order to examine whether FSSB produces positive effects on psychological availability, work-family enrichment, and thriving over time. Furthermore, to avoid the problem of mono-method bias, we encourage researchers to employ different measurement strategies and to collect information about the presence of FSSB, psychological availability, work-family enrichment, and thriving from other sources as well. For example, FSSB could be assessed using the 360-degree evaluation technique by asking multiple key informants in the organizations - such as high-ranking supervisors, colleagues, and subordinates of a given supervisor - about the support provided to collaborators in the management of work-family issues. Another interesting avenue to pursue in the future would be to focus on perceptions of FSSB and work-family enrichment from the perspective of both the focal employee and the partner. This will allow for a more comprehensive understanding of the effects of FSSB in improving the whole family functioning.

Another limitation of this paper is that we focused only on the work-to-family direction of enrichment. While this choice derived from our decision to examine only the relationship between workplace resources and work outcomes (thriving at work), future research is needed to examine whether the experience of family-to-work enrichment generates similar positive effects on individual thriving at work. Furthermore, we also encourage work-family researchers to examine the relationship between FSSB and thriving in the family domain to develop a more comprehensive understanding of how FSSB can enable greater human functioning and growth in multiple regions of an individual's life. Finally, in this study, we considered individuals' need for caring as a potential moderating mechanism. However, other individual factors, such as the individual's boundary management preferences, proactivity, and/or self-determination may affect the extent to which employees are capable of successfully transferring resources from one domain to another and engaging in agentic behaviors that are instrumental to experiencing greater thriving (Carmeli \& Russo, in press). Thus, examining individual differences and how sociopsychological conditions and processes unfold in the development of a sense of thriving can help organizations to design specific contexts in which conditions and processes are better aligned with particular needs and expectations of individuals. 


\section{Conclusions}

This study makes contributions to theory and practice in the area of FSSB, as to the best of our knowledge, it is the first study to empirically demonstrate the benefits of FSSB on psychological availability, work-family enrichment, and thriving at work in non-U.S. countries. Specifically, we found that FSSB facilitates the experience of psychological availability (though only in Study 2) and work-family enrichment, which in turn enables greater individual thriving at work. In addition, we found that the individual need for caring moderates the serial multiple mediator, as the positive effects of FSSB were amplified for employees in the high need for caring condition. Overall, the present study contributes to the goal of developing an understanding of the process and context influencing the effects of FSSB in organizations.

\section{References}

Allen, T. D. 2001. Family-supportive work environments: The role of organizational perceptions. Journal of Vocational Behavior, 58: 414-435.

Allen, T. D., \& Paddock, E. L. 2015. How being mindful impacts individuals' work-family balance, conflict, and enrichment: A review of existing evidence, mechanisms, and future directions. In J. Reb \& P. W. B. Atkins (Eds.), Mindfulness in organizations: Foundations, research, and applications.. Cambridge, UK: Cambridge University Press.

Aryee, S., \& Luk, V. 1996. Work and nonwork influences on the career satisfaction of dual-career couples. Journal of Vocational Behavior, 49: 38-52.

Atwater, L., \& Carmeli, A. 2009. Leader-member exchange, feelings of energy and involvement in creative work. The Leadership Quarterly, 20: 264-275.

Bagger, J., \& Li, A. 2014. How does supervisory family support influence employees' attitudes and behaviors? A social exchange perspective. Journal of Management, 40: 1123-1150.

Biernacki, P., \& Waldorf, D. 1981. Snowball sampling: Problem and techniques of chain referral sampling. Sociological Methods and Research, 10: 141-163.

Brislin, R. W. 1980. Translation and content analysis of oral and written material. In H. C. Triandis \& J. W. Berry (Eds.), Handbook of cross-cultural psychology, vol. 2-Methodology: 349-444. Boston: Allyn \& Bacon.

Buonocore, F., Russo, M., \& Ferrara, M. 2015. Work-family conflict and job insecurity: Are workers from different generations experiencing true differences? Community, Work \& Family, 18: 299-316.

Cameron, K. S., Dutton, J. E., Quinn, R. E., \& Wrzesniewski, A. 2003. Developing a discipline of Positive Organizational Scholarship. In K. S. Cameron, J. E. Dutton, \& R. E. Quinn (Eds.), Positive Organizational Scholarship: Foundations of a new discipline: 361-370. San Francisco: Berrett-Koehler.

Carlson, D. S., Hunter, E. M., Ferguson, M., \& Whitten, D. 2014. Work-family enrichment and satisfaction: Mediating processes and relative impact of originating and receiving domains. Journal of Management, 40: 845-856.

Carlson, D. S., Kacmar, M. K., Wayne, J. H., \& Grzywacz, J. G. 2006. Measuring the positive side of the work-family interface: Development and validation of a work-family enrichment scale. Journal of Vocational Behavior, 68: 131-164.

Carmeli, A., \& Russo, M. in press. The power of micro-moves in cultivating regardful relationships: Implications for work-home enrichment and thriving. Human Resource Management Review, doi:10.1016/j.hrmr.2015.09.007.

Carmeli, A., \& Spreitzer, G. 2009. Trust, connectivity, and thriving: Implications for innovative behaviors at work. The Journal of Creative Behavior, 43: 169-191.

Chen, Q. 2006. Research on work/family conflict of knowledge worker. Unpublished master's thesis, Chongqing University, Chongqing, China.

Cheung, G. W., \& Rensvold, R. B. 2000. Assessing extreme and acquiescence response sets in cross-cultural research using SEM. Journal of Cross-Cultural Psychology, 31: 187-212.

Crain, T. L., \& Hammer, L. B. 2013. Work-family enrichment: A systematic review of antecedents, outcomes, and mechanisms. Advances in Positive Organizational Psychology, 1: 303-328. 
Danner-Vlaardingerbroek, G., Kluwer, E. S., van Steenbergen, E. F., \& van der Lippe, T. 2013. The psychological availability of dual-earner parents for their children after work. Family Relations, 62: 741-754.

Deci, E. L., \& Ryan, R. M. 1985. Intrinsic motivation and self-determination in human behavior. New York: Plenum.

Deci, E. L., \& Ryan, R. M. 2008. Self-determination theory: A macrotheory of human motivation, development, and health. Canadian Psychology/Psychologie Canadienne, 49: 182-185.

Dweck, C. S. 1986. Motivational processes affecting learning. American Psychologist, 41: 1040-1048.

Elliott, E. S., \& Dweck, C. S. 1988. Goals: An approach to motivation and achievement. Journal of Personality and Social Psychology, 54: 5-12.

Fredrickson, B. L. 2001. The role of positive emotions in positive psychology: The broaden-and-build theory of positive emotions. American Psychologist, 56: 218-226.

Greenhaus, J. H., \& Powell, G. N. 2006. When work and family are allies: A theory of work-family enrichment. Academy of Management Review, 31: 72-92.

Greenhaus, J. H., \& Singh, R. 2007. Mentoring and the work-family interface. In B. R. Ragins \& K. E. Kram (Eds.), Handbook of mentoring at work: 519-544. Thousand Oaks, CA: Sage.

Halbesleben, J. R. B., Neveu, J.- P., Paustian-Underdahl, S. C., \& Westman, M. 2014. Getting to the "COR": Understanding the role of resources in conservation of resources theory. Journal of Management, 40: 1334-1364.

Hall, D. T. 1998. Protean careers of the 21st century. Academy of Management Executive, 10: 4-15.

Hammer, L. B., Demsky, C. A., Kossek, E. E., \& Bray, J. W. in press. Work-family intervention research. In T.D. Allen \& L.T. Eby (Eds.), The Oxford handbook of work and family. New York: Oxford Press. doi: 10.1093/oxf ordhb/9780199337538.013.27

Hammer, L. B., Johnson, R. C., Crain, T. L., Bodner, T., Kossek, E. E., Kelly, D., Kelly, E. L., Buxton, O. M., Karuntzos, G., Chosewood, L. C., \& Berkman, L. 2015. Intervention effects on safety compliance and citizenship behaviors: Evidence from the work, family, and health study. Journal of Applied Psychology, doi:10.1037/ apl0000047

Hammer, L. B., Kossek, E. E., Anger, W. K., Bodner, T., \& Zimmerman, K. L. 2011. Clarifying work-family intervention processes: The roles of work-family conflict and family-supportive supervisor behaviors. The Journal of Applied Psychology, 96: 134-150.

Hammer, L. B., Kossek, E. E., Bodner, T., \& Crain, T. 2013. Measurement development and validation of the Family Supportive Supervisor Behavior Short-Form (FSSB-SF). Journal of Occupational Health Psychology, 18: 285-296.

Hammer, L. B., Kossek, E. E., Yragui, N. L., Bodner, T. E., \& Hanson, G. C. 2009. Development and validation of a multidimensional measure of family supportive supervisor behaviors (FSSB). Journal of Management, 35 : 837-856.

Hammer, L. B., Kossek, E. E., Zimmerman, K., \& Daniels, R. 2007. Clarifying the construct of family-supportive supervisory behaviors (FSSB): A multilevel perspective. In P. L. Perrewé \& D. C. Ganster (Eds.), Exploring the work and non-work interface: 165-204. San Francisco: Elsevier Inc.

Hayes, A. F. 2012. PROCESS: A versatile computational tool for observed variable mediation, moderation, and conditional process modeling. Retrieved from http://www.afhayes.com/public/process2012.pdf

Hayes, A. F. 2015. An index and simple test of linear moderated mediation. Multivariate Behavioral Research, 50: $1-22$.

Hayes, A. F., \& Preacher, K. J. 2013. Conditional process modeling: Using structural equation modeling to examine contingent causal processes. In G. R. Hancock \& R. O. Mueller (Eds.), Structural equation modeling. A second course: 217-264. Greenwich, CT: Information Age.

Heckman, J. J. 1979. Sample selection bias as a specification error. Econometrica, 47: 153-161.

Hedström, P., \& Swedberg, R. 1998. Social mechanisms: An introductory essay. In P. Hedström \& R. Swedberg (Eds.), Social mechanisms: An analytical approach to social theory: 1-31. Cambridge, UK: Cambridge University Press.

Hobfoll, S. E. 1989. Conservation of resources. A new attempt at conceptualizing stress. The American Psychologist, 44: 513-524.

House, J. S. 1981. Work stress and social support. Reading, MA: Addison-Wesley.

House, R. J., Hanges, P. J., Javidan, M., Dorfman, P., \& Gupta, V. 2004. Culture, leadership, and organizations: The GLOBE study of 62 societies. Thousand Oaks, CA: Sage Publications. 
Hui, C., Lee, C., \& Rousseau, D. M. 2004. Psychological contract and organizational citizenship behavior in China: Investigating generalizability and instrumentality. Journal of Applied Psychology, 89: 311-321.

Kahn, W. A. 1990. Psychological conditions of personal engagement and disengagement at work. Academy of Management Journal, 33: 692-724.

Kahn, W. A. 1992. To be fully there: Psychological presence at work. Human Relations, 45(4): 321-349.

Kahn, W. A. 1993. Caring for the caregivers: Patterns of organizational caregiving. Administrative Science Quarterly, 38: 539-563.

Kahn, W. A. 2001. Holding environments at work. The Journal of Applied Behavioral Science, 37: 260-279.

Kim, S., \& Las Heras, M. 2012. A qualitative analysis of facilitating conditions for work-family enrichement (IESE working paper). Retrieved from http://www.iese.edu/research/pdfs/DI-0957-E.pdf

Koch, A. R., \& Binnewies, C. 2015. Setting a good example: Supervisors as work-life-friendly role models within the context of boundary management. Journal of Occupational Health Psychology, 20: 82-92.

Kossek, E. E., Pichler, S., Bodner, T. E., \& Hammer, L. B. 2011. Workplace social support and work-family conflict: A meta-analysis clarifying the influence of general and work-family-specific supervisor and organizational support. Personnel Psychology, 64: 289-313.

Kwan, H. K. 2014. Antecedents and outcomes of Family-Supportive Supervisor Behaviors. Unpublished doctoral dissertation, Drexel University, Philadelphia.

Lapierre, L. M., \& Allen, T. D. 2006. Work-supportive family, family-supportive supervision, use of organizational benefits, and problem-focused coping: Implications for work-family conflict and employee well-being. Journal of Occupational Health Psychology, 11: 169-181.

Lapierre, L. M., Spector, P. E., Allen, T. D., Poelmans, S., Cooper, C. L., O’Driscoll, M. P., Sanchez, J. I., Brough, P., \& Kinnunen, U. 2008. Family-supportive organizational perceptions, multiple dimensions of work-family conflict, and employee satisfaction: A test of model across five samples. Journal of Vocational Behavior, 73: 92-106.

Las Heras, M., Trefalt, S., \& Escribano, P. I. 2015. How national context moderates the impact of family-supportive supervisory behavior on job performance and turnover intentions. The Journal of the Iberoamerican Academy of Management, 13: 55-82.

Lirio, P., Lee, M. D., Williams, M. L., Haugen, L. K., \& Kossek, E. E. 2008. The inclusion challenge with reducedload professionals: The role of the manager. Human Resource Management, 47: 443-461.

Lu, J. F., Siu, O. L., Spector, P., \& Shi, K. 2009. Antecedents and outcomes of a four-fold taxonomy of work-family balance in Chinese employed parents. Journal of Occupational Health Psychology, 14: 182-192.

Maslach, C. 2003. Job burnout: New directions in research and intervention. Current Directions in Psychological Science, 12: 189-192.

Matthews, R. A., Mills, M. J., Trout, R. C., \& English, L. 2014. Family-supportive supervisor behaviors, work engagement, and subjective well-being: A contextually dependent mediated process. Journal of Occupational Health Psychology, 19: 168-181.

Matthews, R. A., Wayne, J. H., \& Ford, M. T. 2014. A work-family conflict/subjective well-being process model: A test of competing theories of longitudinal effects. Journal of Applied Psychology, 99: 1173-1187.

May, D. R., Gilson, R. L., \& Harter, L. M. 2004. The psychological conditions of meaningfulness, safety and availability and the engagement of the human spirit at work. Journal of Occupational and Organizational Psychology, 77: 11-37.

Meade, A. W., \& Kroustalis, C. M. 2006. Problems with item partialing for confirmatory factor analytic tests of measurement invariance. Organizational Research Methods, 9: 369-403.

Nix, G., Ryan, R. M., Manly, J. B., \& Deci, E. L. 1999. Revitalization through self-regulation: The effects of autonomous vs. controlled motivation on happiness and vitality. Journal of Experimental Social Psychology, 35: 266-284.

Odle-Dusseau, H. N., Britt, T. W., \& Greene-Shortridge, T. M. 2012. Organizational work-family resources as predictors of job performance and attitudes: The process of work-family conflict and enrichment. Journal of Occupational Health Psychology, 17: 28-40.

Paterson, T. E. D. A., Luthans, F., \& Jeung, W. 2014. Thriving at work: Impact of psychological capital and supervisor support. Journal of Organizational Behavior, 35: 434-446.

Pearce, J. L., Branyiczki, J., \& Bakacsi, G. 1994. Person-based reward systems: A theory of organizational reward practices in reform-communist organizations. Journal of Organizational Behavior, 15: 261-282.

Podsakoff, P. M., MacKenzie, S. B., \& Podsakoff, N. P. 2012. Sources of method bias in social science research and recommendations on how to control it. Annual Review of Psychology, 63: 539-569. 
Poelmans, S., Spector, P. E., Cooper, C. L., Allen, T. D., O’Driscoll, M., \& Sanchez, J. I. 2003. A cross-national comparative study of work/family demands and resources. International Journal of Cross Cultural Management, 3: 275-288.

Porath, C., Spreitzer, G., Gibson, C., \& Garnett, F. G. 2012. Thriving at work: Toward its measurement, construct validation, and theoretical refinement. Journal of Organizational Behavior, 33: 250-275.

Preacher, K. J., Rucker, D. D., \& Hayes, A. F. 2007. Addressing moderated mediation hypotheses: Theory, methods and prescriptions. Multivariate Behavioral Research, 42: 185-227.

Riva, E. 2015. Collective bargaining around work-family issues: Evidence from Italy. Paper presented at the 6th International Community, Work and Family Conference, May 20-22, Malmo, Sweden.

Rothbard, N. P. 2001. Enriching or depleting? The dynamics of engagement in work and family roles. Administrative Science Quarterly, 46: 655-684.

Ruderman, M. N., Ohlott, P. J., Panzer, K., \& King, S. N. 2002. Benefits of multiple roles for managerial women. Academy of Management Journal, 45: 369-386.

Russo, M. 2015. Work-home enrichment and health: An analysis of the mediating role of persistence in goal striving and vulnerability to stress. The International Journal of Human Resource Management, 26: 2486-2502.

Russo, M., Shteigman, A., \& Carmeli, A. in press. Workplace and family support and work-life balance: Implications for individual psychological availability and energy at work. The Journal of Positive Psychology, doi: 10.1080/17439760.2015.1025424.

Saunders, M., Lewis, P., \& Thornhill, A. 2003. Research methods for business students (3rd ed.). Harlow, UK: Pearson.

Schmitt, N., \& Kuljanin, G. 2008. Measurement invariance: Review of practice and implications. Human Resource Management Review, 18: 210-222.

Shor, J., Greenhaus, J. H., \& Graham, K. A. 2013. Context matters: A model of family supportive supervision \& work-family conflict. Academy of Management Annual Meeting Proceedings, 1: 14613.

Spector, P. E., Cooper, C. L., Poelmans, S. A., Allen, T. D., O’Driscoll, M., Sanchez, J. I., Siu, O. L., Dewe, P., Hart, P., \& Lu, L. 2004. A cross-national comparative study of work-family stressors, working hours, and wellbeing: China and Latin America versus the Anglo world. Personnel Psychology, 57: 119-142.

Spreitzer, G. M. 2013. Using a positive organizational scholarship lens to enrich research on work-family relationships. In J. G. Grzywacz \& E. Demerouti (Eds.), New frontiers in work and family research: 1-17. New York: Routledge.

Spreitzer, G., Sutcliffe, K., Dutton, J., Sonenshein, S., \& Grant, A. M. 2005. A socially embedded model of thriving at work. Organization Science, 16: 537-549.

Straub, C. 2012. Antecedents and organizational consequences of family supportive supervisor behavior: A multilevel conceptual framework for research. Human Resource Management Review, 22: 15-26.

ten Brummelhuis, L. L., \& Bakker, A. B. 2012. A resource perspective on the work-home interface: The work-home resources model. The American Psychologist, 78: 1-12.

Vinarski-Peretz, H., \& Carmeli, A. 2011. Linking care felt to engagement in innovative behaviors in the workplace: The mediating role of psychological conditions. Psychology of Aesthetics, Creativity, and the Arts, 5: 43-53.

Voydanoff, P. 2005. Toward a conceptualization of perceived work-family fit and balance: A demands and resources approach. Journal of Marriage and Family, 67: 822-836.

Warner, M., \& Hausdorf, P. 2009. The positive interaction of work and family roles: Using need theory to further understand the work-family interface. Journal of Managerial Psychology, 24: 372-385.

Wayne, J., Casper, W. J., Allen, T. D., \& Matthews, R. 2013. Employee family-supportive organization perceptions and organizational commitment: The mediating role of partner attitudes. Journal of Applied Psychology, 98: 606-622.

Wayne, J. H., Grzywacz, J. G., Carlson, D. S., \& Kacmar, K. M. 2007. Work-family facilitation: A theoretical explanation and model of primary antecedents and consequences. Human Resource Management Review, 17: 63-76.

Wayne, J. H., Musisca, N., \& Fleeson, W. 2004. Considering the role of personality in the work-family experience: Relationships of the Big Five to work-family conflict and facilitation. Journal of Vocational Behavior, 64: 108-130.

Wayne, J. H., Randel, A., \& Stevens, J. 2006. The role of identity and work-family support in work-family enrichment and its work-related consequences. Journal of Vocational Behavior, 69: 445-461. 